\title{
Single pass electrofishing method for assessment and monitoring of larval lamprey populations
}

\author{
Sergio Silva ${ }^{1,2}$, Rufino Vieira-Lanero ${ }^{2}$, Sandra Barca ${ }^{1,2}$, María J. Servia ${ }^{3}$, \\ Javier Sánchez-Hernández ${ }^{1,2}$ and Fernando Cobo ${ }^{1,2}$
}

${ }^{1}$ Departamento de Zoología y Antropología Física. Facultad de Biología. Universidad de Santiago de Compostela. Campus Vida s/n, 15782 Santiago de Compostela, España.

${ }^{2}$ Estación de Hidrobioloxía "Encoro do Con", Castroagudín s/n, 36617 Vilagarcía de Arousa, Pontevedra, España.

${ }^{3}$ Departamento de Biología Animal, Biología Vegetal y Ecología. Facultad de Ciencias. Universidad de A Coruña. Campus da Zapateira s/n, 15008 A Coruña, España.

* Corresponding author: sergio.silva@usc.es

Received: 05/08/2013

Accepted: 10/04/2014

\begin{abstract}
Single pass electrofishing method for assessment and monitoring of larval lamprey populations

Our work aims at calibrating and standardizing the single pass protocol of electrofishing to assess and monitor larval lamprey populations, mainly for European populations of sea lamprey (Petromyzon marinus). The method is considered cost-effective and appropriate for use both on the scale of management decisions (from river or watershed to a regional or national scale) and as a routine assessment tool as required by the European Union Habitats Directive. Additionally, the larval surveys may be reconciled with routine electrofishing surveys for fish species, to further reduce costs. In our case, the escapement of larvae from the sampling area when using electrofishing corresponded to $18 \%$ of larvae and $17 \%$ of larval biomass. The general effectiveness of the protocol to determine the density and biomass of age- 1 and older larvae in the prospected area was $68 \%$ and $70 \%$, respectively. Finally, reference categories for density and biomass of larval populations of P. marinus in NW of the Iberian Peninsula are provided.
\end{abstract}

Key words: Sampling effectiveness, escapement, ammocoete, density, biomass.

\section{RESUMEN}

Método de muestreo por electropesca de una sola pasada para la evaluación y monitorización de las poblaciones de larvas de lamprea

El presente artículo tiene como objetivo la calibración y estandarización del método de pesca eléctrica de una sola pasada para la evaluación y monitorización de poblaciones larvarias de lamprea, en especial para las poblaciones europeas de lamprea marina (Petromyzon marinus). Se trata de un método de bajo coste económico y adecuado tanto para su uso a escala relevante para la gestión de poblaciones (desde río o cuenca hasta escala regional o nacional) como para las evaluaciones periódicas que exige la Directiva Hábitats de la Unión Europea. Los muestreos de larvas pueden ser integrados en los muestreos rutinarios con pesca eléctrica comúnmente utilizados para diferentes especies de peces, con la consiguiente reducción de los costes. Nuestros resultados muestran una fuga media de larvas desde el área de muestreo de un $18 \%$ de los individuos y un $17 \%$ de la biomasa. La efectividad general del protocolo para determinar la densidad y biomasa de larvas de más de un año de edad fue del $68 \%$ y el $70 \%$ respectivamente. Finalmente, se proporcionan categorías de referencia para la densidad y biomasa larvarias de las poblaciones de P. marinus en el NO de la Península Ibérica.

Palabras clave: Efectividad de muestreo, fuga, ammocete, densidad, biomasa. 


\section{INTRODUCTION}

Lampreys are widely distributed throughout temperate zones of both the Northern and Southern hemispheres (Hardisty, 2006). There are 42 current species of lampreys (Renaud, 2011; Mateus et al., 2013), most of which are threatened (Renaud, 1997). In Europe, three of these species, the sea lamprey Petromyzon marinus Linnaeus, 1758, European river lamprey Lampetra fluviatilis (Linnaeus, 1758) and European brook lamprey Lampetra planeri (Bloch, 1784) are included in the Annex II of the European Union Habitats Directive (92/43/EEC), which stipulates that member states have to protect and restore the populations of listed species and associated habitats.

As a consequence, studies on the population status of lamprey species are increasingly common in Europe. Most of these studies focus on the larval stage (Moser et al., 2007), during which individuals spend from 3 to 8 years burrowed in the river sediment (Beamish \& Potter, 1975; Quintella et al., 2003). The optimal habitat for lamprey larvae corresponds to depositional zones of silt or sand with low water velocity and detritus present (Almeida \& Quintella, 2002; Slade et al., 2003), which can normally be found along the margins of the river course.

The methodologies described and used for this purpose are diverse and have been reviewed by Moser et al. (2007). They might be grouped into several common categories: 1) a single pass of non-delimited electrofishing (Slade et al., 2003; Hansen \& Jones, 2008; this paper); 2) a depletion method by electrofishing in a delimiting framework "box" (Harvey \& Cowx, 2003; Nunn et al., 2008; Harvey et al., 2010); and 3) dredging in "box" (Lasne et al., 2010). Moreover, electrofishing with a pump (Bergstedt \& Genovese, 1994) or a water suction dredge (Taverny et al., 2012) can be used in deep areas.

Most larval lamprey surveys typically use a single pass of electrofishing in wadeable areas (Moser et al., 2007) because it is rapid and inexpensive. This methodology provides the observed biomass and density that are subsequently adjusted based on the effectiveness of the method to finally obtain an estimation of the absolute values (Harvey \& Cowx, 2003; Slade et al., 2003; Steeves et al., 2003). The effectiveness of the electrofishing sampling to determine the absolute number of larvae in the prospected area (adjusted larval density) for both invasive and native larval populations of different lamprey species (P. marinus, L. fluviatilis, L. planeri), has been estimated in different studies at close to $50 \%$ (Harvey \& Cowx, 2003; Steeves et al., 2003; Lasne et al., 2010).

Continuing steps towards the refinement of electrofishing protocols for lamprey larvae are the testing for larval escapement and effectiveness, as well as to reduce the sampling effort to achieve the desired objectives (Steeves et al., 2003; Togersen \& Close, 2004; Moser et al., 2007; Hansen \& Jones, 2008). For example, Steeves et al. (2003) suggested the existence of larvae escaping from a non-delimited study area but could not obtain reliable quantitative data on this key aspect.

Thus, the objective of this paper is to further contribute to the calibration and standardization of the single pass protocol of electrofishing to assess and monitor larval lamprey populations at large scale, mainly for European populations of $P$. marinus. For this purpose, a mark-recapture study was conducted to analyze the escapement of individuals from the study area during the electrofishing sampling, as well as the effectiveness of electrofishing to determine the larval density and biomass in the prospected area. Finally, we provide reference categories for density and biomass of larval populations of $P$. marinus in the NW of the Iberian Peninsula, as the result of extensive sampling campaigns run annually from 2007 to 2012.

\section{MATERIALS AND METHODS}

The present study has been conducted in 11 rivers and 34 sampling stations (Fig. 1) situated in Galicia (NW Spain) and with current presence of larval lamprey populations (Cobo et al., 2010). Petromyzon marinus is the only species of lamprey currently cited in the studied rivers (Cobo et 
al., 2010). The following describes in detail the single pass of electrofishing method proposed and used for this study, as well as the analysis of the method effectiveness and the presentation of reference data of larval density and biomass for NW Iberian Rivers.

\section{The single pass electrofishing method}

Sampling was performed in the optimal habitat for lamprey larvae and in summer to ensure the capture of both larvae and transformers (metamorphosing larvae) (Cowx et al., 2009). For fishing, a ring-anode is placed over the sediment surface, and energised for approximately 8-10 second bursts of continuous direct current (pulsed direct current can also be used [Harvey \& Cowx, 2003; Slade et al., 2003]). A brief 3-5 second pause in between bursts allows lampreys to emerge as the power current stops, and once they are in the water column, further bursts immobilise the individuals in order to capture them (Harvey \& Cowx, 2003). The voltage output must be adjusted (100-500 V, reaching 1 ampere) depending upon water conductivity to ensure that ammocoetes are attracted to the anode (Harvey \& Cowx, 2003). Sampling was performed in one or more sediment banks of larval habitat at each site. Selected patches should be completely prospected to know the extent of the surveyed area and to minimize the error produced by larvae entering or leaving the patch.

Following O'Connor (2006), a minimum of 20 minutes of continuous fishing was conducted at each sampling site when no ammocoetes were captured, reaching up to 40 minutes when ammocoetes were captured. Slade et al. (2003) and Hansen \& Jones (2008) used a single pass

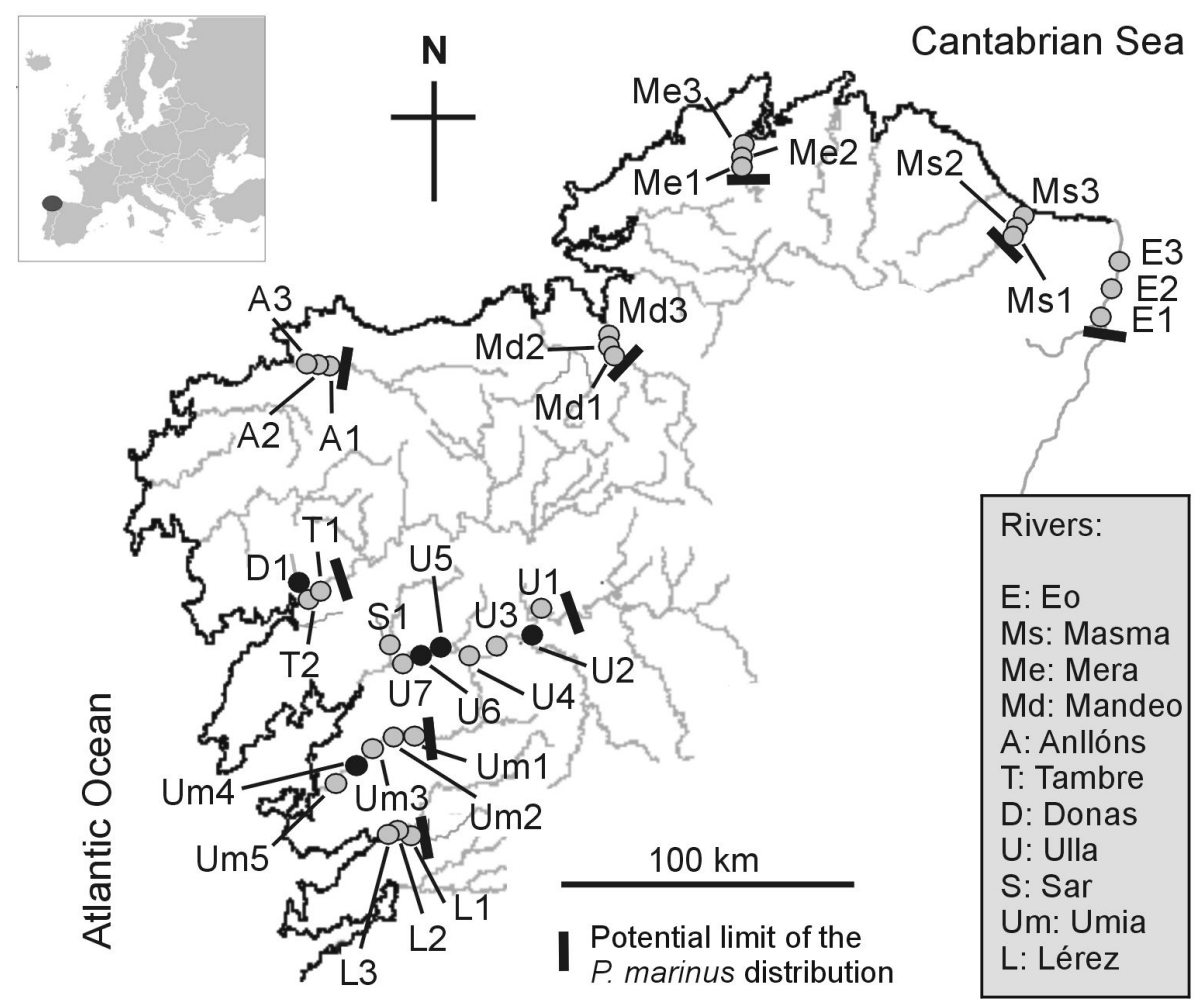

Figure 1. Map of the sampling sites located in 11 rivers in NW Spain. Grey circles: sites only used for obtaining demographic data; black circles: sites used for both obtaining demographic data as well as for studying the effectiveness of the method. Mapa de los puntos de muestreo localizados en 11 ríos del NO de España. Círculos grises: puntos de muestreo utilizados solo para la obtención de datos demográficos. Círculos negros: puntos de muestreo utilizados tanto para la obtención de datos demográficos como para el estudio de la efectividad del método. 
electrofishing method for a fixed surface $\left(30 \mathrm{~m}^{2}\right)$ at a constant speed $\left(0.7\right.$ and $1.0 \mathrm{~m}^{2} \mathrm{~min}^{-1}$, respectively). However, in this type of standardization, density can significantly affect the sampling effectiveness because higher larval densities require longer sampling time per square meter to obtain a similar effectiveness (Steeves et al., 2003). Thus, in order to standardize and avoid this problem, each bank or habitat patch was progressively surveyed, keeping the anode in the same point until no ammocoetes were captured after 4 cycles of burst-stop ( 1 minute), then progressing through the sampling area.

Captured ammocoetes were anaesthetised using a solution of benzocaine $\left(0.3 \mathrm{ml} \mathrm{l}^{-1}\right)$ to reduce handling stress and subsequently measured $( \pm 1 \mathrm{~mm})$ and weighed $( \pm 0.1 \mathrm{~g})$. For each sampling site the observed larval density (ind $\cdot \mathrm{m}^{-2}$ ) and biomass $\left(\mathrm{g} \cdot \mathrm{m}^{-2}\right)$ were calculated by dividing the total catch (individuals and grams, respectively) by the total area sampled. As electrofishing presents a lower catchability of young of the year (YOY) larvae, the larval density and biomass of age-1 and older larvae are also provided (Slade et al., 2003).

\section{Analysis of the single pass electrofishing method by a mark-recapture study}

The mark-recapture methodology (Pine et al., 2003) was used to determine the extent of escapement of larvae from the study area during the electrofishing sampling, as well as the effectiveness of the single pass electrofishing method (SPEM) to determine the larval density and biomass in the prospected area.

For this analysis five sites (U2, U5, U6, Um4 and D1) were sampled between July and September 2012. At each sampling site, we made a first pass for capturing and marking larvae and a second pass for recapturing them. Individuals captured in the first pass were anaesthetized, weighed, measured and tagged with Visible Implant Elastomer (VIE) tags manufactured by Northwest Marine Technology, which can be effectively used to tag larval lampreys (Silver $e t$ al., 2009). Elastomer tags were implanted under the skin using a syringe. After handling, individ- uals were allowed to recover and then returned to their point of capture, verifying that they buried normally. Elastomer tags were easily implanted in lamprey larvae, and only YOY ammocoetes, i.e., under $40 \mathrm{~mm}$ total length (Nunn et al., 2008; unpublished data) were not marked due to their small size. These small larvae were not included in the analysis and were released outside the sampling area.

Once individuals were released back to the sampling area, we waited three hours to allow for their complete recovery (they had already recovered before release) and their redistribution in the sediment before the second pass. The waiting time between the two passes was enough for conducting the two sampling passes on the same day, and for preventing the escapement of individuals by natural movements, which are more common at night (Quintella et al., 2005). At each site, the second pass was performed in the same area, sampling the same surface during the same time. In this second pass, besides measuring and weighing the larvae, we also tracked the presence or absence of a tag in each individual.

Biomass values used for the analysis in this section match with the total biomass $\left(B_{t}\right)$ in grams. To compare the values of number of larvae $(N)$ and total biomass obtained in the first (1) and the second pass (2) the nonparametric Wilcoxon matched-pairs signed ranks test was performed (Barnard et al., 2007) because the data did not conform to normality. Following Steeves et al. (2003) the escapement of larvae $\left(E_{N}\right)$ and total biomass $\left(E_{B t}\right)$ when using the SPEM were calculated as follows:

and

$$
E_{N}=100 \times\left(N_{1}-N_{2}\right) / N_{1}
$$

$$
E_{B t}=100 \times\left(B_{t 1}-B_{t 2}\right) / B_{t 1} .
$$

Adjusted number of larvae $\left(N_{a 2}\right)$ and adjusted total biomass on the second pass $\left(B_{a t 2}\right)$ were calculated as:

$$
\begin{aligned}
N_{a 2} & =\left[N_{1}(\text { total tagged larvae })\right] \times \\
& \times\left[N_{2} / N_{2}(\text { only recaptures })\right]
\end{aligned}
$$

and

$$
\begin{aligned}
B_{a t 2} & =\left[B_{t 1}(\text { total biomass tagged })\right] \times \\
& \times\left[B_{t 2} / B_{t 2}(\text { only recaptures })\right]
\end{aligned}
$$


(modified from Margalef, 1974). Then, to calculate the adjusted number of larvae $\left(N_{a 1}\right)$ and adjusted total biomass on the first pass $\left(B_{a t 1}\right)$ the effect of the escapement must be taken into account as follows:

$$
N_{a 1}=100 \times N_{a 2} /\left(100-E_{N}\right)
$$

and

$$
B_{a t 1}=100 \times B_{a t 2} /\left(100-E_{B t}\right) .
$$

Finally the effectiveness of the method to estimate the absolute number of larvae $\left(E f_{N}\right)$ and biomass $\left(E f_{B t}\right)$ were calculated as:

$$
E f_{N}=100 \times N_{1} / N_{a 1}
$$

and

$$
E f_{B t}=100 \times B_{t 1} / B_{a t 1} .
$$

The Pearson correlation test has been used to establish the relationship between effectiveness and the biotic parameters of larval density and biomass at each sampling point.

\section{Reference categories for larval density and biomass in NW Iberian Peninsula}

From 2007 to 2012 annual surveys were carried out in 34 different sampling sites (25 sites in 2007; 29 in 2008; 30 in 2009; 18 in 2010; 22 in 2011; 5 in 2012) located in 11 rivers of Galicia (NW Spain) with larval populations of $P$. mari$n u s$, including the sampling sites also prospected to study the effectiveness of the electrofishing method (Fig. 1). The spectrum of demographic data obtained by electrofishing allowed the establishment of reference categories for larval density and biomass of $P$. marinus in this region. To establish the reference categories, values of larval density and biomass were collated and separated by percentiles following Pedicillo et al. (2010) and Sánchez-Hernández et al. (2012). Thus, five categories were established:

1. Very poor - when the value of the variable is below the 10th percentile.

2. Poor - when the value of the variable is between the 10th and the 30th percentile.

3. Moderate - when the value of the variable is between the 30th and the 70th percentile.

4. High - when the value of the variable is between the 70th and the 90th percentile.

5 . Very high - when the value of the variable exceeds the 90th percentile.

In addition to reference categories for all larvae captured, the reference categories for age-1

Table 1. Results obtained by mark-recapture of lamprey larvae in five sampling sites. $N$ : number of individuals; $B_{t}$ : total biomass (observed biomass); 1: first pass; 2: second pass; $N_{a}$ and $B_{a t}$ : adjusted density and total biomass (estimate of the absolute value); $E$ :

\begin{tabular}{|c|c|c|c|c|c|}
\hline Locality & $\mathrm{U} 2$ & U5 & U6 & Um4 & D1 \\
\hline$N_{1}$ & 159 & 102 & 285 & 132 & 95 \\
\hline$N_{2}$ & 147 & 90 & 238 & 87 & 77 \\
\hline$B_{t 1}(\mathrm{~g})$ & 390.1 & 111.2 & 954.6 & 219.4 & 197.3 \\
\hline$B_{t 2}(\mathrm{~g})$ & 345.2 & 94.5 & 755.4 & 166.0 & 170.1 \\
\hline$E_{n}(\%)$ & 7.5 & 11.8 & 16.5 & 34.1 & 18.9 \\
\hline$E_{B t}(\%)$ & 11.5 & 15.0 & 20.9 & 24.3 & 13.8 \\
\hline$\%$ recaptures $_{2}(N)$ & 89.1 & 85.6 & 73.9 & 65.7 & 92.2 \\
\hline$\%$ recaptures $2\left(B_{t}\right)$ & 89.9 & 86.9 & 76.5 & 67.8 & 96.0 \\
\hline$B_{a t 2}(\mathrm{~g})$ & 433.8 & 128.0 & 1247.0 & 323.7 & 205.5 \\
\hline$B_{a t 1}(\mathrm{~g})$ & 490.3 & 150.6 & 1575.7 & 427.7 & 238.4 \\
\hline$N_{a 2}(\mathrm{~g})$ & 178.4 & 119.2 & 385.4 & 201.0 & 103.0 \\
\hline$N_{a 1}(\mathrm{~g})$ & 193.0 & 135.1 & 461.5 & 305.0 & 127.1 \\
\hline Effectiveness $_{B t}(\%)$ & 79.6 & 73.8 & 60.6 & 51.3 & 82.8 \\
\hline Effectiveness $_{N}(\%)$ & 82.4 & 75.5 & 61.8 & 43.3 & 74.7 \\
\hline
\end{tabular}
escapement. Resultados obtenidos mediante el marcado-recaptura de larvas en cinco puntos de muestreo. N: número de individuos; $\mathrm{B}_{\mathrm{t}}$ : biomasa total (biomasa observada); 1: primera pasada; 2: segunda pasada; $\mathrm{N}_{\mathrm{a}}$ y $\mathrm{B}_{\mathrm{at}}$ : densidad y biomasa total ajustada (estimación del valor absoluto); E: escape. 
and older larvae are also provided, as it is advisable to provide data on this part of the population due to the lower catchability of YOY larvae by the electrofishing method (Slade et al., 2003). Statistical analyses were performed using IBM SPSS Statistics 20.0 software.

\section{RESULTS}

\section{Analysis of the single pass electrofishing method by a mark-recapture study}

The main results obtained are shown in Table 1 . A total of 1412 larvae were captured in this study, the sampling time and the sampled area (mean $\pm 95 \%$ confidence interval) being $51 \pm 5.2 \mathrm{~min}$ (range: $43-60$ ) and $16 \pm 3.5 \mathrm{~m}^{2}$ (range: 11-22) for each site $(N=5)$ and pass. The average escapement produced during electrofishing (mean $\pm 95 \%$ confidence interval) was $17.8 \pm 12.57 \%$ (range: $7.5-34.1$ ) for the number of larvae, and $17.1 \pm 6.60 \%$ (range: 11.5-24.3) for total biomass. Consequently, a significant difference between values obtained in the first and second pass, both for larval density and larval biomass, was recorded (Wilcoxon matched-pairs signed ranks test, $p<0.05)$. For larval density and total biomass, an average effectiveness of $67.5 \pm 19.21 \%$ (range: 43.3-82.4) and $69.6 \pm 16.51 \%$ (range: $51.3-82.8$ ) were obtained, respectively. No correlations were found between effectiveness and larval density or biomass recorded at each sampling point (Pearson correlation test: $0.516 ; p=0.373$ for density; $-0.292 ; p=0.633$ for biomass).

\section{Reference categories for larval density and biomass in NW Iberian Peninsula}

Reference categories for density and biomass of larval populations of $P$. marinus in NW of the Iberian Peninsula are shown in Table 2. To obtain these reference categories, 10269 larvae were captured in 34 different sampling sites situated in 11 rivers of Galicia (NW Spain). Due to the standardization selected to minimize the variation of effectiveness between locations (fishing the same square meter until no ammocoetes were captured after one minute; see section "The single pass electrofishing method"), the sampling rate was higher in areas with higher larval densities, progressing faster in sampling points with low densities. The average time of fishing (mean $\pm 95 \%$ confidence interval) at each site was $38 \pm 1.1$ min (range: 19-60), and the average sampled surface was $18 \pm 2.0 \mathrm{~m}^{2}$ (range: 4-75), prospecting at a rate of 2.9 $\pm 0.25 \mathrm{~min}^{2}$ (range: 0.5-10.0). The mean value (mean $\pm 95 \%$ confidence interval) of the observed larval density at each site was 6.1 \pm 0.98 ind $\cdot \mathrm{m}^{-2}$ (range: 0.03-39.0). Similarly, the mean observed biomass was $11.9 \pm 2.17 \mathrm{~g}$ $\cdot \mathrm{m}^{-2}$ (range: $0.1-90.5$ ). For age- 1 and older larvae, the mean observed density and biomass were $5.9 \pm 0.97$ ind $\cdot \mathrm{m}^{-2}$ (range: $0.03-39.0$ ) and $11.9 \pm 2.17 \mathrm{~g} \cdot \mathrm{m}^{-2}$ (range: $\left.0.1-90.5\right)$.

\section{DISCUSSION}

Usefulness and effectiveness of the single pass protocol of calibrated electrofishing has been

Table 2. Reference categories for observed density and biomass of larval populations of $P$. marinus in NW of the Iberian Peninsula, for both all larvae (all) and age-1 and older larvae $(\geq 1+)$. D: larval density (ind $\left.\cdot \mathrm{m}^{-2}\right)$; B: larval biomass $\left(\mathrm{g} \cdot \mathrm{m}^{-2}\right)$. Categorías de referencia para la densidad y biomasa observadas de poblaciones larvarias de P. marinus en el NO de la Península Ibérica, tanto para todas las larvas (all) como para las larvas de un año de edad o más $(\geq 1+)$. D: densidad larvaria (ind $\left.\cdot m^{-2}\right) ; B:$ biomasa larvaria $\left(\mathrm{g} \cdot \mathrm{m}^{-2}\right)$.

\begin{tabular}{lcccc}
\hline & Observed D (all) & Observed D $(\geq 1+)$ & Observed B (all) & Observed B $(\geq 1+)$ \\
\hline Very high & $>13.6$ & $>12.8$ & $>26.9$ & $>26.9$ \\
High & $8.1-13.6$ & $7.5-12.8$ & $13.5-26.9$ & $13.3-26.9$ \\
Moderate & $2.6-8.0$ & $2.6-7.4$ & $4.6-13.4$ & $4.6-13.2$ \\
Poor & $0.7-2.5$ & $0.7-2.5$ & $1.6-4.5$ & $1.6-4.5$ \\
Very poor & $<0.7$ & $<0.7$ & $<1.6$ & $<1.6$ \\
\hline
\end{tabular}


tested in order to survey lamprey larvae of $P$. marinus in wadeable rivers. This is a cost-effective method considered appropriate for both its use on the scale relevant to management decisions (from river or watershed to a regional or national scale) and its use as a routine assessment tool. As a consequence, it might be a suitable methodology for the large scale assessment and monitoring of larval lamprey populations required by the European Union Habitats Directive (rivers should be sampled at least each six years). It is also compatible with traditional electrofishing sampling routines, as electrofishing is most likely the most commonly used tool to carry out assessments on fish population parameters (Cowx et al., 2009). The staff, material required, timing of surveys and even the sampling localities, might be the same for both cases, allowing for a further reduction of costs (Harvey \& Cowx, 2003).

Larval density can affect the sampling effectiveness because higher larval densities require longer sampling time per square meter to obtain a similar effectiveness (Steeves et al., 2003). Due to that, it is important to standardize the sampling effort (see section "The single pass electrofishing method") in order to limit the differences of effectiveness between locations. Effectiveness can be used to adjust the observed results to obtain an approximate overview of the situation at the river basin scale (Harvey \& Cowx, 2003; Slade et al., 2003; Steeves et al., 2003). For comparisons of larval biomass or density between populations, the average values of the watershed or river should be used because the error caused using a fixed effectiveness to adjust the results is mitigated by the inclusion of values from different localities (Steeves et al., 2003). Even so, when adjusting observed data, it is advisable to use the average effectiveness \pm the $95 \%$ confidence interval to obtain an average estimate together with a more reliable (probability of $95 \%$ ) interval of adjusted values.

As expected, the effectiveness of the method for age- 1 and older larvae densities $(68 \%)$ are slightly higher than the $\sim 50 \%$ effectiveness described for larval density using all larvae (Harvey \& Cowx, 2003; Lasne et al., 2010). Due to reduced influence of the YOY larvae on the biomass (Cobo et al., 2010), the effectiveness provided here for age- 1 and older larvae biomass (70\%) is considered suitable for adjusting observed biomass of all larvae. For the same reason, it is advisable to provide biomass values in demographic studies, as this variable is still rarely used in lamprey larvae assessments.

The lower catchability of YOY individuals by the electrofishing method (Lasne et al., 2010) prevents its use in robust recruitment studies. However, the presence of these individuals is highly variable between years and in space depending on different factors, and this limits the information provided by this variable (Hansen et al., 2003). They concentrate within the vicinity of spawning areas, resulting in high densities in these locations but not in the rest of the watershed (Derosier et al., 2007). Thus, the precise study of recruitment require specific protocols such as dredging carried out every year and detailed samplings near spawning areas (Lasne et al., 2010). The labour, time and cost required by some methods, such as dredging, suction, or the depletion method in "box", limit their potential as a routine assessment tool (Torgersen \& Close 2004; Lasne et al., 2010; Taverny et al., 2012). As a consequence, those studies are usually limited to one river or basin. In fact, in most of their distribution range, available information on lamprey species is limited to presence-absence data, usually obtained from surveys targeting other fish species but inadequate for lamprey populations (Cowx et al., 2009). On the contrary, the methodology we propose aims at obtaining data at a much larger scale and to provide medium term trends. The effort and costs needed for obtaining this lower but acceptable accuracy is a clear advantage for routine assessment (Hansen \& Jones, 2008; Fenichel \& Hansen, 2010).

There is no sampling method that can be used or is optimal for all cases. Each method has different limitations that prevent or hinder its use across the range of larval habitats. A surface area of habitat that is too small, narrow marginal areas, areas near overhanging trees, the presence of roots, vegetal debris or stones and deep or fast-flowing areas all prevent the use of a delimiting framework (box) or nets (Nunn et al., 2008; Harvey et al., 2010; 
Lasne et al., 2010). Where the use of the "box" is not possible, Harvey et al. (2010) use a nondelimited single pass of electrofishing.

As the amount of available information increases, the methodology and the sampling design may be either improved or adjusted as necessary, or complemented by other methods to best meet management and conservation goals (Hansen \& Jones, 2008). The use of this protocol might be particularly important in areas where the distribution or presence of the species is not known, or where larval densities are low, because in such cases the use of more accurate but also more costly and time consuming methodologies is totally devoid of meaning. It would be very convenient to analyze the effectiveness of the method in other regions and habitats to know whether the results obtained are similar to ours.

\section{Reference categories for larval density and biomass in NW Iberian Peninsula}

Cowx et al. (2009) suggest a larval density classification for establishing the favourable or unfavourable conservation status of $P$. marinus, $L$. fluviatilis and L. planeri populations in the UK. For P. marinus, the minimum larval density value proposed for favourable conservation status was 0.2 ind $\cdot \mathrm{m}^{-2}$ at optimal habitat and $0.1 \mathrm{ind} \cdot \mathrm{m}^{-2}$ at basin scale. As recommended by these authors, this classification should be adapted to other regions and species as more data become available (Cowx et al., 2009; Harvey et al., 2010). In the NW of the Iberian Peninsula even observed values (non-adjusted) of rivers with populations at the worst conservation state exceed the threshold described by these authors for sea lamprey (Cobo et al., 2010), suggesting that populations of $P$. marinus in NW Spain are larger than those found in UK.

All larvae collected in this study were identified as $P$. marinus. Therefore, all the results and assumptions in this paper relate primarily to this species. However, except the reference categories for population parameters, both the methodology and the results and assumptions described may be valid for other lamprey species, as their larval stage is very similar (Hardisty, 2006).

\section{ACKNOWLEDGEMENTS}

The authors thank the staff of the Station of Hydrobiology of the USC "Encoro do Con" for their participation in the surveys. This study has been partially supported by the project 10PXIB2111059PR of the Xunta de Galicia and the project MIGRANET of the Interreg IV B SUDOE (South-West Europe) Territorial Cooperation Programme (SOE2/P2/E288). S. B. is supported by a grant from the PTA-MICINN (PTA2011-5566-I), Plan Nacional de I+D+i 2008-2011. The authors are also grateful to two anonymous referees for their helpful comments.

\section{REFERENCES}

ALMEIDA, P. R. \& B. R. QUINTELLA. 2002. Larval habitat of the sea lamprey (Petromyzon marinus L.) in the River Mondego (Portugal). In: Freshwater fish conservation: options for the future. M. J. Collares-Pereira, M. M. Coelho \& I. G. Cowx (eds): 121-130. Fishing News Books, Blackwell Science, Oxford, UK.

BARNARD, C., F. GILBERT \& P. MCGREGOR. 2007. Asking Questions in Biology, $3^{\text {rd }}$ ed. Prentice Hall, London, UK.

BEAMISH, F. W. H. \& I. C. POTTER. 1975. The biology of the anadromous sea lamprey (Petromyzon marinus) in New Brunswick. Journal of Zoology, 177: 57-72.

BERGSTEDT, R. A. \& J. H. GENOVESE. 1994. New technique for sampling sea lamprey larvae in deepwater habitats. North American Journal of Fisheries Management, 14: 449-452.

COBO, F., S. SILVA, R. VIEIRA-LANERO, M. J. SERVIA, J. SÁNCHEZ-HERNÁNDEZ, S. BARCA, S. RIVAS, M. COUTO, P. GÓMEZ, D. J. NACHÓN, C. MORQUECHO, L. LAGO \& M. C. COBO. 2010. Estado de conservación das poboacións de lamprea mariña en ríos de Galicia. Xunta de Galicia, Consellería do Medio Rural, Dirección Xeral de Conservation da Natureza, Santiago de Compostela, Spain.

COWX, I. G., J. P. HARVEY, R. A. NOBLE \& A. D. NUNN. 2009. Establishing survey and monitoring protocols for the assessment of conservation status of fish populations in river Special Areas of Conservation in the UK. Aquatic Conservation: Ma- 
rine and Freshwater Ecosystems, 19: 96-103.

DEROSIER, A. L., M. L. JONES \& K. T. SCRIBNER. 2007. Dispersal of sea lamprey larvae during early life: relevance for recruitment dynamics. Environmental Biology of Fishes, 78: 271-284.

FENICHEL, E. P. \& G. J. A. HANSEN. 2010. The opportunity cost of information: An economic framework for understanding the balance between assessment and control in sea lamprey management. Canadian Journal of Fisheries and Aquatic Sciences, 67: 209-216.

HANSEN, G. J. A. \& M. L. JONES. 2008. A rapid assessment approach to prioritizing streams for control of Great Lakes sea lampreys (Petromyzon marinus): a case study in adaptive management. Canadian Journal of Fisheries and Aquatic Sciences, 65: 2471-2484.

HANSEN, M. J., J. V. ADAMS, D. W. CUDDY, J. M. RICHARDS, M. F. FODALE, G. L. LARSEN, D. J. OLLILA, J. W. SLADE, T. B. STEEVES, R. J. YOUNG \& A. ZERRENNER. 2003. Optimizing larval assessment to support sea lamprey control in the Great Lakes. Journal of Great Lakes Research, 29: 766-782.

HARDISTY, M. W. 2006. Lampreys: Life without Jaws. Forrest Text, Ceredigion, UK.

HARVEY, J. P. \& I. COWX. 2003. Monitoring the river, brook and sea lamprey, Lampetra fluviatilis, L. planeri and Petromyzon marinus. Conserving Natura 2000 Rivers Monitoring Series No. 5, English Nature, Peterborough. http://www.english nature.org.uk/lifeinukrivers/publications/lamprey monitoring.pdf.

HARVEY, J. P., R. A. NOBLE, A. D. NUNN, R. J. TAYLOR \& I. G. COWX. 2010. Monitoring sea lamprey Petromyzon marinus ammocoetes in SAC rivers: a case study on the River Wye. In: Conservation Monitoring in Freshwater Habitats-A Practical Guide and Case Studies. C. Hurford, M. Scheider \& I. G. Cowx (eds): 193-206. Springer.

LASNE, E., M. R. SABATIE, J. TREMBLAY, L. BEAULATON \& J. M. ROUSSEL. 2010. A new sampling technique for larval lamprey population assessment in small river catchments. Fisheries Research, 106: 22-26.

MARGALEF, R. 1974. Ecologia. Omega, Barcelona, Spain.

MATEUS, C. S., M. J. ALVES, B. R. QUINTELLA \& P. R. ALMEIDA. 2013. Three new cryptic species of the lamprey genus Lampetra Bonnaterre, 1788 (Petromyzontiformes: Petromyzon- tidae) from the Iberian Peninsula. Contributions to Zoology, 82: 37-53.

MOSER, M. L., J. M. BUTZERIN \& D. B. DEY. 2007. Capture and collection of lampreys: the state of the science. Reviews in Fish Biology and Fisheries, 17: 45-56.

NUNN, A. D., J. P. HARVEY, R. A. A. NOBLE \& I. G. COWX. 2008. Condition assessment of lamprey populations in the Yorkshire Ouse catchment, North-East England, and the potential influence of physical migration barriers. Aquatic Conservation: Marine and Freshwater Ecosystems, 18: 175-189.

O'CONNOR, W. 2006. A baseline survey of juvenile lamprey populations in the River Feale catchment. Irish Wildlife Manuals No. 22, National Parks and Wildlife Service, Department of Environment, Heritage and Local Government, Dublin, Ireland. http://www.npws.ie/publications/irishwildlifemanuals/IWM22.pdf.

PEDICILlO, G., A. CAROSI, L. GHETTI \& $\mathrm{M}$. LORENZONI. 2010. Population size structure indices and growth standards for Salmo (trutta) trutta Linnaeus, 1758 in Central Italy. Knowledge and Management of Aquatic Ecosystems, 399: 8-22.

PINE, W. E., K. H. POLLOCK, J. E. HIGHTOWER, T. J. KWAK \& J. A. RICE. 2003. A review of tagging methods for estimating fish population size and components of mortality. Fisheries, 28: 10-23.

QUINTELLA, B. R., N. O. ANDRADE \& P. R. ALMEIDA. 2003. Distribution, larval stage duration and growth of the sea lamprey ammocoetes, Petromyzon marinus L., in a highly modified river basin. Ecology of Freshwater Fish, 12: 286-293.

QUINTELLA, B. R., N. O. ANDRADE, R. ESPANHOL \& P. R. ALMEIDA. 2005. The use of PIT telemetry to study movements of ammocoetes and metamorphosing sea lampreys in river beds. Journal of Fish Biology, 66: 97-106.

RENAUD, C. B. 1997. Conservation status of Northern Hemisphere lampreys (Petromyzontidae). Journal of Applied Ichthyology, 13: 143-148.

RENAUD, C. B. 2011. Lamprey of the World. An Annotated and Illustrated Catalogue of Lamprey Species Known to Date. FAO Species Catalogue for Fishery Purposes No. 5, Rome.

SÁNCHEZ-HERNÁNDEZ, J., M. J. SERVIA, R. VIEIRA-LANERO, S. BARCA-BRAVO \& F. COBO. 2012. References data on the growth and population parameters of brown trout in siliceous rivers 
of Galicia (NW Spain). Limnetica, 31: 273-288. SILVER, G. S., C. L. LUZIER \& T. A.WHITESEL. 2009. Detection and longevity of uncured and cured visible implant elastomer tags in larval Pacific Lampreys. North American Journal of Fisheries Management, 29: 1496-1501.

SLADE, J. W., J. V. ADAMS, G. C. CHRISTIE, D. W. CUDDY, M. F. FODALE, J. W. HEINRICH, H. R. QUINLAN, J. G. WEISE, J. W. WEISSER \& R. J. YOUNG. 2003. Techniques and methods for estimating abundance of larval and metamorphosed sea lampreys in great lakes tributaries, 1995 to 2001. Journal of Great Lakes Research, 29: 137151.

STEEVES, T. B., J. W. SLADE, M. F. FODALE, D.
W. CUDDY \& M. L. JONES. 2003. Effectiveness of using backpack electrofishing gear for collecting sea lamprey (Petromyzon marinus) larvae in great lakes tributaries. Journal of Great Lakes Research, 29: 161-173.

TAVERNY, C., G. LASSALLE, I. ORTUSI, C. ROQUEPLO, M. LEPAGE \& P. LAMBERT. 2012. From shallow to deep waters: habitats used by larval lampreys (genus Petromyzon and Lampetra) over a western European basin. Ecology of Freshwater Fish, 21: 87-99.

TORGERSEN, C. E. \& D. A. CLOSE. 2004. Influence of habitat heterogeneity on the distribution of larval pacific lamprey (Lampetra tridentata) at two spatial scales. Freshwater Biology, 49: 614-630. 